\title{
O ENIGMA DO EU: APONTAMENTOS CRÍTICOS ACERCA DO CONCEITO DE NARRATIVIDADE
}

\author{
Adelino Ferreira ${ }^{1}$ \\ Universidade Federal de Minas Gerais (UFMG) \\ (i) https://orcid.org/0000-0003-3171-9950
}

\begin{abstract}
RESUMO:
$\mathrm{O}$ conceito de narratividade tem sido frequentemente utilizado entre filósofos da mente que pretendem compreender criticamente a questão da identidade pessoal na filosofia contemporânea. Trata-se de pensá-la como uma teia narrativa que se desenrola durante a vida. Ao personagem narrado chamaríamos 'eu'. Daniel Dennett e David Velleman são dois eminentes defensores deste tipo de visão. O presente artigo visa expor brevemente os pontos de aproximação entre estes autores, mas principalmente discutir um importante momento de afastamento entre eles, especialmente no que tange à ideia de um módulo central narrativo, introduzida por Velleman e criticada por Dennett. Como contraposição à visão narrativa será, por fim, contraposta outra proposta de se pensar a identidade pessoal, como negação da narratividade, presente no pensamento de Galen Strawson.
\end{abstract}

PALAVRAS-CHAVE: Narratividade; Identidade Pessoal; Eu.

\section{SELF'S PUZZLE: CRITICAL NOTES ABOUT NARRATIVITY}

\begin{abstract}
:
The concept of narrativity has often been used among philosophers of mind that claim to critically understand the issue of personal identity in contemporary philosophy. The point is to think of it as a narrative web that unfolds throughout life. The narrator character we call 'self'. Daniel Dennett and David Velleman are two prominent proponents of this proposition. This article aims to briefly expose the nearest points between these authors, but mainly discuss an important moment of distance between them, especially about the idea of a narrative core module, introduced by Velleman and criticized by Dennett. As contrary approach it will be finally opposed

\footnotetext{
${ }^{1}$ Mestrando em Filosofia pela Universidade Federal de Minas Gerais (UFMG), Minas Gerais - Brasil. Bolsista do CNPq. E - email: adefer86@yahoo.com.br
} 
another proposal about personal identity, such as denial of narrativity present in Galen Strawson works.

KEYWORDS: Narrativity; Personal Identity; Self.

\section{Introdução}

Daniel Dennett, no texto The Origins of Selves (1989), aborda uma questão que há muito foi introduzida na história da filosofia: o que é o eu? A pergunta remonta a Descartes, que afirmou ser o eu: uma 'coisa' pensante ${ }^{2}$. Segundo Dennett: "Desde Descartes, no século 17, nós temos uma visão do eu como um fantasma imaterial que possui e controla um corpo da mesma forma como você possui e controla o seu carro" ${ }^{3 "}(1989$, p. 163). Sem entrar no mérito se a imagem do eu como um 'fantasma' é a melhor opção disponível em termos alegóricos, fato é que, com a filosofia cartesiana, instaurou-se uma forte tradição dualista na reflexão sobre o eu.

$\mathrm{Na}$ contemporaneidade, com o avanço da neurociência, a ideia de um dualismo de substância, tal qual o cartesiano - corpo e mente entendidos como substâncias independentes - perdeu força entre os teóricos da mente. Estudos empíricos apresentados, entre outros, por Antônio Damásio, em sua célebre obra $O$ Erro de Descartes (1994), colocaram em cheque o modelo cartesiano de se pensar a relação entre o corpo e a mente. Exemplos destes estudos são as pesquisas feitas com pacientes que tiveram partes do cérebro danificadas - o operário Fineas Gage é o exemplo mais famoso - que mostraram claramente uma inter-relação entre as partes do cérebro afetadas e as mudanças comportamentais surgidas.

Outra ideia criticada entre os filósofos que atualmente se dedicam a tais discussões é o que Dennett chama de 'teatro cartesiano'. Trata-se de entender a mente como um tipo de sala de controle central, onde uma espécie de homúnculo comandaria as ações humanas. Este homúnculo (o eu, de fato) teria abertas diante de si todas as possibilidades de ação, guiando o corpo como o puxar de cordas de uma marionete. $\mathrm{O}$ eu seria, pois, como a pérola do cérebro, o locus onde se concentrariam as decisões dos seres humanos.

Diante das críticas a tais formas de se pensar o eu, como tratar a questão? Como pensar tal problema na contemporaneidade? Seria o caso de abandonar totalmente o conceito de eu ou buscar uma nova compreensão

\footnotetext{
${ }^{2}$ A reflexão cartesiana sobre o eu como coisa pensante está presente na obra Meditações sobre a Filosofia Primeira, em especial na segunda meditação, em que se diz: "Mas o que sou eu, portanto? Uma coisa que pensa. Que é uma coisa que pensa? É uma coisa que duvida, que concebe, que afirma, que nega, que quer, que não quer, que imagina também e que sente" (DESCARTES, 1983, p. 47).

3 A tradução desta e das demais citações presentes no texto é de responsabilidade do autor do trabalho. Os textos originais estão em língua inglesa.
} 
para o mesmo? Uma possibilidade para se repensar a questão é a partir do conceito de narratividade. $\mathrm{O}$ eu não seria, pois, algo situado, mas o personagem de uma biografia, na qual está contida sua história. Vários autores se dispuseram a pensar desta forma, entre eles Daniel Dennett e David Velleman. É a partir do pensamento destes dois filósofos que se pretende discorrer, aqui, sobre a questão do eu.

No capítulo da obra Self to Self (2006), intitulado Self as Narrator, Velleman explicita sua tese que, segundo ele, é em muito parecida com a de Daniel Dennett. Contudo, ele dá um passo a mais em sua teoria do eu, passo este não acompanhado por Dennett: Velleman postula a existência de um módulo responsável pela produção da narrativa. Este trabalho pretende, pois, confrontar a posição de Velleman à de Dennett (apresentada em uma série de textos que serão aqui citados) e levantar questionamentos acerca da necessidade ou não de se postular tal módulo narrativo. Uma possível crítica a Velleman a ser explorada é que, ao recorrer à ideia de um módulo narrativo, ele cairia novamente na ideia de teatro cartesiano, ou de homúnculo controlador da qual pretende fugir. Desta forma, a posição de Dennett, talvez, explicaria melhor a narratividade sem um comprometimento como o de Velleman.

A ideia de narratividade, contudo, também não é consensual entre aqueles que pensam a questão do eu. Galen Strawson, em um artigo intitulado Against Narrativity (2004), levanta várias críticas a tal noção. Ele tem como adversários uma série de autores que pensam a narratividade de uma forma mais ou menos substancial. Strawson considera a posição de Dennett uma das mais fortes na defesa da narratividade. Suas críticas serão feitas especialmente ao modelo dennettiano, embora, como se pretende mostrar, trata-se mais de uma defesa da possibilidade de se pensar o eu de forma não narrativa do que propriamente uma crítica definitiva aos modelos narrativos. O pensamento de Strawson, expresso no referido artigo, será considerado na última parte deste trabalho.

\section{O coelho na cartola: primeira noção de self}

Em Self as Narrator, Velleman inicia sua exposição com uma metáfora para diferenciar seu pensamento do pensamento dennettiano. Segundo tal metáfora, o eu seria como um coelho imaginário que pula de uma cartola. Tudo não passaria de um truque. Mas, quem seria o responsável pelo truque, uma vez que não há mágico? Segundo Dennett, seria a própria cartola. Nestes termos, não existiria o mágico (uma entidade criadora) e o coelho (o eu) seria imaginário. O que haveria de real em toda a história seria a cartola (o cérebro que faz o truque).

Velleman concede a Dennett a plausibilidade da noção de eu como um protagonista fictício da autobiografia de uma pessoa, mas não da conclusão de que fictício significa 'não real'. 
Minha única discordância com Dennett será que, enquanto ele vê uma biografia como fictícia e, consequentemente, falsa na caracterização de seu protagonista, eu a vejo como fictícia e verdadeira. Nós inventamos a nós mesmos, devo argumentar, mas nós realmente somos os personagens que inventamos (VELLEMAN, 2006, pp. 205-206).

Esta é uma diferença fundamental entre os dois autores, como se verá ao longo do texto. Isso porque Dennett busca enfatizar em todos os seus textos acerca do tema, o caráter ficcional do eu, em um sentido forte. Em The Self as Center of Gravity (1986), ele afirma que uma boa imagem para a compreensão do eu é pensá-lo como um centro de gravidade. Centro de Gravidade é um abstractum, ou seja, não possui realidade física. É uma ficção teórica com grande utilidade prática. Entendido desta forma, perguntar sobre o que o eu é, realmente, ou onde ele está no cérebro, é um erro categorial (DENNETT, 1986, p. 2).

Dennett pensa a criação desse eu ficcional em termos evolutivos:

Nossa fundamental tática de autoproteção, autocontrole e autodefinição não está em tecer redes e construir barragens, mas em contar histórias, e mais particularmente inventar e controlar a história que nós contamos aos outros - e a nós mesmos - sobre quem somos. E assim como aranhas não têm que pensar, consciente e deliberadamente, sobre como tecer suas teias, e assim como castores, ao contrário de engenheiros humanos profissionais, não consciente e deliberadamente planejam as estruturas que constroem, nós (ao contrário de contadores de histórias profissionais) não consciente $\mathrm{e}$ deliberadamente descobrimos quais narrativas contar e como contá-las (DENNETT, 1991, p. 418).

Nota-se aí a ideia de que segundo o autor, o cérebro não sabe o que está fazendo quando conta uma história. $\mathrm{O}$ eu é apenas o personagem desta história criada, como o personagem de Moby Dick, que pede para ser chamado Ishmael. Ishmael não existe, sua história não é real. Só que diferente do autor de Moby Dick, que sabe o que está fazendo, nosso cérebro é cego à tarefa que executa. Trata-se de uma tese forte, para muitos, inclusive, contraintuitiva. Para esclarecer seu argumento, Dennett cria uma experiência de pensamento que será importante para a discussão de Velleman. O intuito é mostrar que não é necessário haver um biógrafo consciente do que faz.

A experiência de pensamento trata de um robô que faz a narração de sua vida: a história de um personagem chamado Gilbert. Dennett afirma que Gilbert é um eu fictício, cujo criador não é um eu, mas apenas uma máquina (não uma máquina pensante, e sim uma máquina 'tola' que, mesmo assim, consegue escrever uma novela razoável). O que é importante na história de 
Gilbert, para Dennett, é que não há um controlador geral, ou em outras palavras, uma 'unidade de ação'. É essa, em suma, a diferença entre os autores. Dennett prefere entender a narratividade de forma multiinstanciada, sem um controle geral. Para defender esta forma de compreensão ele utiliza do exemplo da colônia de cupins:

O que é particularmente intrigante sobre a colônia de cupins é que ela é um exemplo de um sistema complexo capaz de funcionar de uma maneira que parece ser totalmente "proposital e integrada" simplesmente por ter muitos subsistemas executando suas próprias funções sem supervisão. De fato, a maioria dos sistemas executa seu trabalho sem supervisão. Na verdade, a maioria dos sistemas na Terra que parecem ter controles centrais (e é utilmente descrita como os tendo) não os tem (DENNETT, 1989, p.6).

A analogia com a colônia de cupins é extremamente importante aos propósitos dennettianos, isto porque se consegue mostrar, assim, um sistema natural que funciona sem comando central, de forma organizada. Mostrando que isso é possível, mesmo parecendo algo contraintuitivo, Dennett transfere o ônus da prova àquele que quiser postular a necessidade de controles centrais para organismos aparentemente organizados. Velleman, como se verá, está no outro campo do diálogo, postulando a existência de um comando central, entendido como módulo narrativo.

\section{A interdependência entre narração e comportamento}

Um dos principais argumentos empíricos apresentados por Dennett para sustentar sua posição é comportamento apresentado por pessoas com Transtorno de Múltiplas Personalidades (TMP). Em todos os seus textos relacionados à temática do eu, ele recorre a tal transtorno como uma forte evidência para a tese de que o cérebro cria ilusões, a que chamamos de eu. O artigo Speaking of Our Selves (1998), escrito com Nicolas Humphrey, é todo dedicado a tal discussão.

Pessoas com TMP manifestam diferentes personalidades, possuem diferentes nomes, sotaques, modos de se vestir e andar. Como é afirmado no artigo citado acima: "Existem dados que sugerem diferenças de reações alérgicas e funcionamento da tireoide [nas pessoas com esse transtorno]" (DENNETT; HUMPHREY, 1998, p. 49). Quando uma personalidade assume o comportamento, a pessoa passa a agir de forma completamente distinta da personalidade anterior. Isto parece corroborar a ideia dennettiana do eu como ficção.

Neste ponto, Velleman apresenta uma objeção à explicação de Dennett, cuja resposta os levará para uma segunda definição de eu: 
Se um ser humano apenas contém "muitos sistemas executando sua própria função" então por que um deles não pode executar sua função com o pé enquanto outro executa a sua função com a boca, de modo que se ande com o andar de uma personalidade enquanto se conta a história de outra? (2006, p. 2001).

A resposta a esta questão é a interdependência entre a narração e o comportamento que se narra. Isto, para Dennett, não é um problema, uma vez que ele afirma textualmente que: "Tentamos fazer com que todo nosso material seja coerente com uma única boa história" (1986, p. 8). Os múltiplos sistemas trabalhando juntos, mesmo sem um centro de controle, agem de forma a construir uma história integrada. Isto é fruto de um processo evolutivo, biológico, como já afirmado. Contudo, é importante para Velleman reforçar o ponto da interdependência entre comportamento e narração dadas suas pretensões teóricas.

A partir da interdependência entre comportamento e narração, Velleman explicita o papel causal da narração no comportamento do narrado. Ele volta ao caso do robô Gilbert e afirma que se, por exemplo, o robô agradece por ter sido tirado de um armário onde estava trancado, ele o faz porque foi tirado de lá. Ou seja, há uma ligação entre os eventos passados e presentes que formam uma cadeia causal sem a qual não se poderia falar verdadeiramente de narração.

Velleman salienta o papel causal da narração e o faz olhando para o passado (agradeço porque fui tirado do armário) e também para o futuro (é porque o robô diz que vai para o armário que ele vai). Como evidência da força causal da narração, é apresentado um estudo que mostra: "que indivíduos tendem a prever que irão votar na próxima eleição a uma taxa muito mais elevada do que a taxa de participação média; mas o comparecimento às urnas entre aqueles que previram que votariam é maior do que a média" (2006, p. 214).

A interdependência entre narração e comportamento bem como o papel causal exercido pela narrativa mostram, segundo Velleman, que o eu não é uma ficção no sentido de um personagem ficcional, mas a própria pessoa autobiografada (2006. p. 214). Ele diz que, embora Dennett quase se aproxime desta posição, não o faz de forma clara. Velleman cita uma passagem do capítulo da obra Consciouness Explained (1991), Reality of Selves, para mostrar o flerte de Dennett com uma posição de tal tipo ${ }^{4}$.

\footnotetext{
4 “Um eu, de acordo com a minha teoria, não é qualquer velho ponto matemático, mas uma abstração definida pelas diversas atribuições e interpretações (incluindo autoatribuições e autointerpretações) que compuseram a biografia do corpo vivo cujo Centro de Gravidade Narrativa ele (o eu) é. Sendo assim, ele desempenha um papel singularmente importante na economia cognitiva em curso daquele corpo vivo, porque, de todas as coisas no ambiente das quais um corpo ativo deve fazer modelos mentais, nenhuma é mais essencial que o modelo que o agente faz de si próprio.” (DENNETT, apud VELLEMAN, 2006, p. 215).
} 
Contudo, outra passagem no final do mesmo capítulo, não citada por Velleman, parece esclarecer melhor a discussão:

\begin{abstract}
Mas eu não existo?
Claro que você existe. Aí está você, sentado na cadeira, lendo meu livro e levantando desafios. E, muito curiosamente, sua personificação atual, embora uma precondição necessária para sua criação, não é necessariamente um requisito para sua existência ser prolongada indefinidamente. Agora, se você fosse uma alma, uma pérola de substância imaterial, poderíamos "explicar" sua potencial imortalidade apenas por meio de postulação disso como uma propriedade inexplicável, uma virtus dormitiva ineliminável da coisa-alma. Se você fosse uma pérola de substância material, algum grupo de átomos espetacularmente especial no seu cérebro, sua mortalidade dependeria das forças físicas que o mantém unido (poderíamos perguntar aos físicos qual "meia-vida" um eu é). Se você pensa em si mesmo como um centro de gravidade narrativa, por outro lado, sua existência depende da persistência daquela narrativa (DENNETT, 1991, p. 430).
\end{abstract}

Dennett não vê problema em afirmar que este eu, criado pelo cérebro, é a pessoa que existe, lê livros, faz planos, age de acordo com sua narração etc.. O problema, para Dennett, é querer saber o que este eu é, realmente: "O principal personagem ficcional no centro daquela autobiografia é o seu eu. E se você ainda quer saber o que o eu realmente é, você está cometendo um erro categorial." (1986, p. 8). Velleman retira uma conclusão das evidências levantadas que, talvez, não esteja autorizado a retirar. Ele parece concluir do fato de que há uma correlação entre narração e comportamento que deve haver um sistema unificado de comando fazendo este trabalho. Para entender melhor esta questão, cabe avançar para a terceira e última noção de eu apresentada no texto de Velleman. Esta já não é compartilhada com Dennett.

\title{
0 módulo narrativo
}

Velleman, para postular a existência de um 'módulo narrativo', recorre novamente à história do robô Gilbert. Ele constrói um cenário para seu argumento da seguinte maneira: Imagine que o robô Gilbert, funcionando com suas diversas sub-rotinas, está preso no armário. Uma possível sub-rotina a ser ativada é a que pode ser chamada de 'medo'. Ela recomendará ao robô quebrar a porta, para sair daquele lugar. O fato de uma sub-rotina - dentre as várias possíveis - comandar o comportamento de Gilbert se dá por um motivo aparentemente claro: é aquela que mais se conforma com a história narrada (2006, p. 216). Ele, então, afirma: 


\begin{abstract}
Assim, tendo atribuído um estado interno a si mesmo ("Estou ficando com medo"), o robô é influenciado a agir de acordo com tal atribuição. Como um ser humano, ele tende a manifestar medo não apenas porque ele está "sentindo" isso, mas também porque ele "pensa" que isso é o que o que ele está sentindo. (VELLEMAN, 2006, p. 216).
\end{abstract}

Aqui parece ter sido incluída uma espécie de capacidade reflexiva na história de Gilbert. Todo esse processo seria comandado por um módulo narrativo que escreve a autobiografia do robô. Velleman afirma que: "O módulo deve ser projetado para produzir um texto que seja consonante com os fatos e suficiente consonante consigo próprio para se qualificar como uma história." (2006, p. 216). A questão que se coloca é: qual a necessidade de tal módulo que faça este trabalho central? E mais: quais evidências Velleman apresenta para sustentar a sua existência?

Ao postular 'estados internos' ao robô Gilbert, Velleman parece se aproximar muito da ideia de consciência, que ele próprio diz no começo do texto não querer discutir. Seria possível, além disso, o questionamento: o que diferencia a terceira noção de eu da segunda? Parece que simplesmente foi introduzida uma noção de consciência (Gilbert sai do armário porque ele tem consciência de que está com medo e age em consequência disso) e um controle central, chamado de módulo narrativo que parece cumprir as funções típicas da imagem do homúnculo controlador presente no cérebro.

Velleman parece deixar explícita tal imagem quando afirma que: "À medida que a competição entre aquelas sub-rotinas não é muito desequilibrada, o módulo narrativo está em posição para decidir para onde vai Gilbert." (2006, p. 218). Aqui a imagem dennettiana da colônia de cupins e de softwares sofisticados pode ser levantada contra Velleman. É possível perfeitamente explicar tal comportamento sem postular um módulo que decide. É curioso notar que a ideia de que 'é o módulo que decide', é muito próxima da noção de um pequeno Gilbert, controlando centralmente todo o sistema.

Um ser com um módulo narrativo é, para Velleman, um agente autônomo, que age por razões que poderiam ser entendidas como vários motivos competindo para controlar o comportamento do autor. Novamente, não haveria, para Dennett, problema com tal ideia, apenas com a imagem de um módulo central que centraliza tal empreitada. Na noção dennettiana, não há um módulo narrativo, mas uma narração que se desenrola de forma coerente, modelando o comportamento: "parece que nós somos todos romancistas virtuosos, que nos encontramos envolvidos em todos os tipos de comportamento, mais ou menos unificados, mas às vezes desunificados, e sempre colocamos neles as melhores 'faces' que pudermos." (DENNETT, 1986, p. 8).

Quando Velleman afirma que: "O agente de autonarração é um pouco como um ator de improvisação, encenando um papel que ele inventa 
à medida que interpreta." (2006, p. 221) ele formula uma imagem que parece se assemelhar muito à ideia de um homúnculo comandando o cérebro. Tratar-se-ia da ideia do narrador como uma espécie de 'pérola do cérebro', algo que o próprio autor não está disposto a aceitar. Parece também a postulação de um ser consciente de suas ações: "O autonarrador é um improvisador ingênuo, inventando um papel que expressa seus verdadeiros motivos em resposta a eventos reais" (2006, p. 221).

Ao fim de Self as Narrator, Velleman resume nestes termos seus pontos de aproximação e afastamento com Dennett:

\begin{abstract}
Posso apoiar a afirmação de Dennett que o eu é um personagem fictício. O meu ponto de desacordo com Dennett é sobre a alegação de que, por ser fictício, este personagem não existe de fato. Dennett pensa que o autor da vida real de uma autobiografia é significativamente diferente do personagem retratado como protagonista. Eu penso que o autor de uma autobiografia é como o protagonista, já que o protagonista é retratado como um personagem se autoimprovisando, como o inventor-ator de sua própria história - ou, como prefiro dizer, como um agente autônomo (2006, p. 222).
\end{abstract}

Desta discordância surgem outras duas: (i) Enquanto Dennett nega a existência de um controle central, Velleman acredita que o próprio Dennett está comprometido com tal ideia, na forma de uma inteligência narrativa; (ii) Enquanto Dennett afirma que postular um controle central é admitir o teatro cartesiano ou uma 'pérola no cérebro', Velleman acredita que o controle central é a inteligência narrativa, que é diferente das noções de teatro cartesiano ou 'pérola no cérebro'. Ele termina, pois, por afirmar: "Embora Dennett tente negar a unidade da autonarração do agente, ele se compromete expressamente com a unidade da narrativa - com a proposição de que 'Tentamos fazer com que todo o nosso material seja coerente em uma única boa história"” (DENNETT, apud VELLEMAN, 2006, p. 222).

Esta última citação parece deixar clara a diferença entre a posição dos dois autores. Dennett parece estar comprometido, sim, com a unidade da narrativa. Uma narrativa que é, no pensamento dele, ficcional. O que Dennett não está disposto a aceitar - e Velleman precisaria, talvez, de mais elementos para sustentar - é que esta narrativa é real e comandada por um módulo narrativo. Aqui, cabe voltar a uma citação de Dennett já citada neste trabalho: "parece que nós somos todos romancistas virtuosos, que nos encontramos envolvidos em todos os tipos de comportamento, mais ou menos unificados, mas às vezes desunificados, e sempre colocamos neles as melhores 'faces' que pudermos" (DENNETT, 1986, p. 8). A diferença entre o 'novelista virtuoso' e o 'improvisador ingênuo' é que o primeiro não precisa estar consciente de nada, ou para evitar a discussão sobre consciência, não precisa ser unificado. 
A posição de Dennett, do ponto de vista de uma economia ontológica, parece explicar o mesmo, postulando menos entidades:

\begin{abstract}
Afinal de contas, quando o sistema de controle do comportamento de um ser humano torna-se prejudicado seriamente, isso pode revelar que a melhor história hermenêutica que podemos contar sobre aquele indivíduo é a de que há mais de um personagem 'habitando' aquele corpo. Isso é perfeitamente possível na visão de eu que venho apresentando; não requer nenhum milagre metafísico extravagante (DENNETT, 1986, p. 8).
\end{abstract}

A teoria dennetiana parece conseguir explicar melhor os casos de Transtorno de Múltiplas Personalidades (TMP) ao postular um sistema funcional sem controle central (como os que existem em colônias de cupins e softwares modernos). Ela também comporta uma explicação evolucionária (que Dennett explicita em comparação a teias das aranhas e diques de castores). Ela parece conseguir, ainda, explicar o comportamento humano sem cair em qualquer suspeita de teatro cartesiano.

Velleman, por sua vez, parece dar um passo a mais em sua noção de narratividade e talvez precisasse responder a algumas questões: qual o ganho conceitual em se postular uma inteligência narrativa como um módulo central de comando? Em que medida isto não é, efetivamente, uma volta ao teatro cartesiano, uma vez que se trata de algo real, embora fictício? Quais as evidências sustentam tal visão de módulo central de comando em detrimento de um sistema sem controle central?

Talvez a divergência entre os autores possa estar, na verdade, no que eles entendem por real e eles estejam defendendo, de fato, posições mais parecidas do que assumem. Contudo, à primeira vista, a posição de Dennett, parece explicar com mais recursos e menos entidades metafísicas o conceito de narratividade. Deste modo, tendo sua teoria como uma boa representante da tradição narrativa, cabe confrontá-la com algumas críticas de um autor que está no campo oposto desta discussão: G. Strawson.

\title{
Contra a narratividade: o outro lado da discussão
}

Galen Strawson, em seu artigo Against Narrativity, se posiciona contra a ideia de narratividade. Em sua estratégia argumentativa ele inicialmente afirma que há duas possíveis concepções de narratividade: (i) prescritiva (também chamada de tese psicológica): "Existe um consenso generalizado de que os seres humanos normalmente veem, ou vivem, ou experimentam a vida como uma narrativa ou história de algum tipo, ou pelo menos como uma coleção de histórias" (2004, p. 428); e (ii) normativa (também chamada de tese ética): "Isto indica que experimentar ou conceber a vida como uma narrativa é uma coisa boa; uma visão ricamente narrativa é 
essencial para uma vida bem vivida, para a verdade ou total pessoalidade" (2004, p. 428). Strawson é contrário a ambas.

Para investigar o conceito de narratividade, Strawson apresenta quatro formas distintas e progressivas de se pensar a autoexperiência. Elas vão desde a forma diacrônica (mais básica), passando pelo que ele chama de 'tendência a encontrar uma forma', pela 'tendência de contar uma história', até uma capacidade que Strawson denomina 'revisão'. Cabe percorrer rapidamente o percurso estabelecido pelo autor em seu texto para perceber por que ele discorda de todas estas formas e aponta Dennett como alguém que aceita todas elas.

Strawson afirma inicialmente ser possível pensar a autoexperiência de duas formas distintas: diacrônica ou episódica. Em síntese, a forma diacrônica é aquela da pessoa que pensa ser a mesma que estava no passado e que estará no futuro. Trata-se de uma autoexperiência de continuidade (persistência) no tempo. Já a forma episódica é aquela apresentada por aquele que não postula a si mesmo tal persistência, por alguém que não vê sua vida em termos narrativos. (STRAWSON, 2004, p. 430).

A forma diacrônica talvez seja a mais comum entre as pessoas, como admite Strawson, mas ele ressalta que alguns fatores podem modificar a forma de autocompreensão dos indivíduos, além da existência de diferentes padrões em diferentes culturas. Segue-se, no texto, uma apologia a indivíduos episódicos frente a acusações de que esta seria uma forma inferior de se viver. Episódicos não negligenciariam totalmente o passado, mas o experimentariam de forma incorporada, como um músico que sabe tocar uma peça sem se recordar como a aprendeu. (STRAWSON, 2004, p. 432). Tal parte do texto parece querer justificar o direito de um indivíduo se considerar episódico. Todavia, não são apresentados muitos elementos que demonstrem que tal concepção é comumente compartilhada pelas pessoas.

É apresentada, pois, uma crítica ao conceito de narração, baseada nas próprias experiências do autor. Ele afirma:

E eu ainda não sinto de modo algum a minha vida como uma narrativa com forma, ou mesmo como uma narrativa sem forma. Absolutamente não. Também não tenho qualquer grande ou especial interesse no meu passado. Também não tenho uma grande preocupação com o meu futuro. (...) É claro para mim que os acontecimentos no meu passado remoto não aconteceram comigo*. Mas isto equivale a quê? Certamente não significa que eu não tenha nenhuma memória autobiográfica dessas experiências passadas. Eu tenho. Também não quer dizer que as minhas memórias autobiográficas não têm o que os filósofos chamam de um caráter 'do ponto de vista interno' (STRAWSON, 2004, p. 433). 
Este comigo*, no contexto explicitado pelo autor, é o eu atual, experimentado por ele no presente. Sua intenção é mostrar certa descontinuidade. O não reconhecimento do eu*, no passado ou no futuro, como o mesmo personagem, indicaria que o conceito de narratividade não pode ser utilizado de forma adequada. Tratar-se-ia, pois, de uma imagem não narrativa do eu. Ele afirma ainda que: "O modo como eu sou agora é profundamente moldado pelo meu passado, mas apenas as consequências presentes da moldagem do passado importam, não o passado, como tal." (STRAWSON, 2004, p. 438). Esta visão é uma negação da ideia de narratividade.

Strawson, então, como forma de refinar seu conceito de narratividade, inclui um segundo elemento à caracterização do conceito: a tendência que um eu narrativo tem de 'encontrar uma forma'. Ou seja, para ser narrador, não basta a consciência de permanência no tempo, mas sim uma capacidade, ou tendência a estabelecer um padrão de continuidade nesta permanência (2004, pp. 441-442). Um terceiro elemento introduzido é a tendência a 'contar uma história'. Ele seria a capacidade de reportar a própria vida como uma sequencia homogênea de eventos, conscientes, escolhendo os fatos a serem relatados (STRAWSON, 2004, pp. 442-443).

O último elemento a ser introduzido é chamado de 'revisão'. Este é entendido como a mudança da visão de alguém sobre os fatos de sua própria vida. É a tese de que, ao contar a sua própria vida o eu se vê engajado na formação de uma história coerente e, para isso, pode revisar alguns fatos e acontecimentos ocorridos consigo, de forma a conformá-los com o todo da história. (STRAWSON, 2004, pp. 443-445). Strawson afirma, contudo, que esta não é uma característica necessária da narração, podendo o eu contar uma história sem revisão.

Tendo apresentado os elementos que compõe a narratividade, segundo sua descrição, Strawson afirma que Dennett é um autor que está comprometido com todos estes elementos (diacronicidade, tendência a encontrar uma forma, a contar uma história e a revisão), alguns outros autores aceitam umas e negam outras e ele próprio nega todas. A condição suficiente para a narratividade seria, contudo, apenas tendência a contar uma história. Strawson, então, tenta mostrar que é possível uma autocompreensão não narrativa e que isto não é negativo. Pelo contrário, ele afirma que o modo narrativo de pensar o eu pode, este sim, ser prejudicial em alguns aspectos.

A ideia de narratividade não seria necessária para uma 'vida examinada' nos moldes socráticos, afirma Strawson. Ele também defende que a psicoterapia não precisa ser um projeto narrativo, uma vez que ela necessitaria mais de uma 'cesta variada de entendimentos' do que a uma narrativa que, muito provavelmente, incluiria falsificações (2004, p. 448). Ele assim reitera sua apologia à forma episódica de autocompreensão: 


\begin{abstract}
Eu sou um produto do meu passado, incluindo o meu passado bem distante, em muitos aspectos profundamente importantes. Mas disso simplesmente não se segue que a autocompreensão, ou o melhor tipo de autocompreensão, deve assumir uma forma narrativa, ou mesmo, uma forma histórica. Se eu fosse cobrado a fazer a minha autocompreensão explicitamente, eu poderia muito bem ilustrar meu ponto de vista sobre mim mesmo por referência a coisas que eu (GS) tenha feito, mas certamente não iria se seguir daí que eu tenha uma perspectiva diacrônica e, menos ainda, uma narrativa. (STRAWSON, 2004, p. 449).
\end{abstract}

O fim do texto de Strawson é marcado por uma alusão à amizade entre Montaigne e Etiene de La Boétie, como contraponto à acusação de que uma personalidade episódica não apresentaria sinais de amizade ou lealdade. Strawson vê em Montaigne um grande episódico, julgado por sua falta memória que, no entanto, não acarretava qualquer tipo de indiferença, falta de afeição ou ingratidão. O recurso à experiência montaigneana parece, mais uma vez, reforçar o caráter apologético fortemente presente em seu texto.

\title{
Considerações finais
}

Narratividade é uma das formas de se pensar o conceito de eu na contemporaneidade. Daniel Dennett, por meio de seu materialismo evolucionista tenta formular uma noção que seja ao mesmo tempo coerente com as pesquisas empíricas mais recentes e sensível ao problema filosófico da identidade pessoal. Ao postular uma noção de narratividade sem comando central narrativo consciente, ele procura evitar os labirintos teóricos que levam a visões talvez já superadas acerca da mente, como a ideia de um teatro aberto no qual seria possível representar todas as ações a serem executadas pelo corpo.

Um dos argumentos mais interessantes apresentados por Dennett em sua teoria é a existência de organismos organizados sem um controle geral, como softwares modernos e colônias cupins. Estes são exemplos concretos que ele pode apresentar a seu adversário teórico. A teoria dennettiana busca levar solucionar o enigma da consciência da forma mais deflacionária possível, postulando o menor número de entidades para dar conta das explicações acerca do caráter distintivo do mental.

A posição de David Velleman tem, por sua vez, a virtude de construir uma boa história para explicar as relações causais que vinculam a narração e o comportamento dos indivíduos. A narrativa não apenas conta o que foi executado, mas prediz as ações futuras do agente. Velleman destaca o papel das diferentes sub-rotinas no comportamento do robô Gilbert que seriam correlatas, nos humanos, às motivações e razões para a ação.

Velleman chama muito bem a atenção para o caráter unificado da história que se conta. Contudo, o que se procurou mostrar neste trabalho foi 
um possível questionamento da necessidade em se postular um módulo unificado para realizar este trabalho. Ao postular a realidade do eu, em contraposição à posição de Dennett, Velleman talvez tenha dado um passo a mais, ou quem sabe, esteja apenas entendendo a pergunta pela realidade do eu de uma forma distinta de Dennett. Pode ser que, visto da forma de Velleman, seja possível perguntar pela realidade do eu, embora, na leitura feita, não se chegou à conclusão que ele apresenta elementos suficientes para isso.

Por fim, a posição de Strawson, situada na outra margem da disputa teórica, tem como virtude a possibilidade de se salvaguardar personalidades que não se veem de forma narrativa. Como já dito, a leitura feita do artigo Against Narrativity deixou uma impressão fortemente apologética, principalmente diante do que o autor chamou de concepção normativa de narratividade. Strawson procurou mostrar que é possível uma vida reflexiva, amistosa e capaz de reciprocidade sem que se tenha que postular os elementos encontrados em perspectivas narrativas de autocompreensão.

Não foi o intento desta discussão desconsiderar uma ou outra posição acerca do que se chamou aqui de enigma do eu, mas sim apresentar algumas das posições presentes no debate contemporâneo de um problema com origens modernas. A partir da trilha aberta por Descartes, muitos autores se dedicaram a este importante problema filosófico que hoje une (mas também distancia) filósofos da mente, neurocientistas e psicólogos. Este trabalho buscou apenas apresentar um pequeno recorte de uma perspectiva aparentemente promissora no tratamento da questão: a abordagem narrativa acerca da discussão sobre o eu.

\section{Referências bibliográficas}

DAMÁSIO, António R. O Erro de Descartes: Emoção, Razão e o Cérebro Humano. 3. ed. São Paulo: Companhia das Letras, 2012. (primeira edição, 1994).

DENNETT, Daniel C. The Self as a Center of Narrative Gravity. In: F. Kessel, P. Cole and D. Johnson, eds, Self and Consciousness: Multiple Perspectives, Hillsdale, NJ: Erlbaum, 1992. Danish translation, "Selvet som fortællingens tyngdepunkt," Philosophia, 15, 275-88, 1986. Disponível em:

<http://isites.harvard.edu/fs/docs/icb.topic565657.files/9/Dennett\%20self\%2 0as\%20center\%20of\%20gravity.pdf> Acesso em: 10 maio 2015. pp. 1-9.

. The Origins of Selves. Cogito 3. pp. 163-73, Autumn 1989.

Reprinted in Daniel Kolak and R. Martin, eds., Self \& Identity: Contemporary Philosophical Issues, Macmillan, 1991. Disponível em: <http://cogprints.org/257/1/originss.htm> Acesso em: 10 maio 2015. pp. 111.

The Reality of Selves. In: Consciousness Explained. Hachette Book Group USA: New York, 1991.

O enigma do eu: apontamentos críticos acerca do conceito de narratividade - Adelino Ferreira 
; HUMPHREY, Nicholas. Speaking of Our Selves. Brainchildren: Essays on Designing Minds. Cambridge, MA: MIT Press, 1998.

DESCARTES, René. Meditações. (Os Pensadores) São Paulo: Abril Cultural, 1983.

STRAWSON, Galen. Against Narrativity. Ratio (new series) XVII 4 December 2004. pp. 428-452.

VELLEMAN, J. David. Self as Narrator. In: Self to Self: Select Essays. Cambridge University Press: New York, 2006. 